\title{
Genetic diversity within Lactobacillus sakei and Lactobacillus curvatus and design of PCR primers for its detection using randomly amplified polymorphic DNA
}

\author{
Françoise Berthier ${ }^{1 \dagger}$ and Stanislav D. Ehrlich²
}

\author{
Author for correspondence: Françoise Berthier. Tel: +333847363 13. Fax: + 33384373781 . \\ e-mail: berthier@poligny.inra.fr
}

Laboratoire de Recherches sur la Viande ${ }^{1}$ and Laboratoire de Génétique Microbienne2, Institut National de la Recherche Agronomique, Domaine de Vilvert, 78352 Jouy-en-Josas Cedex, France

\begin{abstract}
The genotypic and phenotypic diversity among isolates of the Lactobacillus curvatus/Lactobacillus graminis/Lactobacillus sakei group was evaluated by comparing RAPD data and results of biochemical tests, such as hydrolysis of arginine, D-lactate production, melibiose and xylose fermentation, and the presence of haem-dependent catalase. Analyses were applied to five type strains and to a collection of 165 isolates previously assigned to $L$. sakei or $L$. curvatus. Phenotypic and RAPD data were compared with each other and with previous DNA-DNA hybridization data. The phenotypic and genotypic separation between $L$. sakei, $L$. curvatus and $L$. graminis was clear, and new insights into the detailed structure within $L$. sakei and $L$. curvatus were obtained. Individual strains could be typed by RAPD and, after the elimination of similar or identical isolates, two sub-groups in both $L$. curvatus and $L$. sakei were defined. The presence or absence of catalase activity further distinguished the two $L$. curvatus sub-groups. By cloning and sequencing specific RAPD products, pairs of PCR primers were developed that can be used to specifically detect $L$. curvatus, $L$. sakei and each of the $L$. sakei sub-groups.
\end{abstract}

Keywords: RAPD, PCR primers, genetic diversity, Lactobacillus sakei, Lactobacillus curvatus

\section{INTRODUCTION}

Much taxonomic data on Lactobacillus sakei and Lactobacillus curvatus strains are currently available as a result of their technological interest. Both species were isolated from diverse habitats such as prepackaged finished dough and fermented plant and meat material (Kandler \& Weiss, 1986). They have been shown to play essential roles in meat preservation and fermentation processes (Egan, 1983; Hammes et $a l ., 1990)$, in which they are increasingly used as starter cultures. In this context, however, some important points remain to be considered for an objective selection of strains of interest: (i) rapid classification and identification of unknown isolates; (ii) evaluation of genetic diversity among strains and the impact of

tPresent address: SRTAL, BP 89, 39801 Poligny Cedex, France.

Abbreviations: RAPD, randomly amplified polymorphic DNA; UPGMA, unweighted pair group method using arithmetic means. diversity on the relevant properties of microorganisms; and (iii) strain typing to assess genetic stability over time.

The phenotypic and genotypic diversity within $L$. curvatus and L. sakei, as well as the close relatedness of the two species, have been revealed by many studies. Phenotypically, $L$. curvatus and $L$. sakei were often split into sub-groups (Schillinger \& Lücke, 1987; Samelis et al., 1995; Klein et al., 1996) when physiological and/or biochemical data were analysed. The main criteria used to differentiate $L$. sakei from $L$. curvatus varied among laboratories, which resulted in the assignment of a strain to either L. sakei, L. curvatus, a group of atypical L. sakei/L. curvatus, or no assignment at all, depending on the criteria used (Schillinger \& Lücke, 1987; Döring et al., 1988; Montel et al., 1991; Samelis et al., 1995; Klein et al., 1996). For example, differences in the assigned names were observed for the arginine-positive/melibiose-negative and arginine-negative/melibiose-positive strains. In addition, a protein pattern-based sub-grouping was 
Table 1. Relevant characteristics of the strains used in this study

\begin{tabular}{|c|c|c|c|c|c|c|}
\hline $\begin{array}{l}\text { Name as } \\
\text { received }\end{array}$ & Strain number & Isolated from: & Source* & $\begin{array}{c}\text { Phenotypic } \\
\text { group } \dagger\end{array}$ & $\begin{array}{l}\text { RAPD } \\
\text { group } \ddagger\end{array}$ & Proposed name \\
\hline L. curvatus & FY $113 \S$ & Meat & 8 & 3 & Al & L. curvatus \\
\hline L. curvatus & T $402 \S$ & Pork meat & 5 & 3 & A1 & L. curvatus \\
\hline L. curvatus & YMG $348 \S$ & Meat & 8 & 3 & Al & L. curvatus \\
\hline L. curvatus & СТC 243 & Sausage & 3 & 2 & A2 & L. curvatus \\
\hline L. curvatus & CTC 253 & Sausage & 3 & 2 & A2 & L. curvatus \\
\hline L. bavaricus & СТС 423 , СТC 424, СТC 448 & Sausage & 3 & 1 & A2 & L. curvatus \\
\hline L. curvatus & DSM 20019 & Milk & 1 & 2 & A2 & L. curvatus \\
\hline L. curvatus & J $116 \S$ & Sausage & 6 & 2 & A2 & L. curvatus \\
\hline L. bavaricus & LTH 1143, LTH 1782, LTH 2053 & Sauerkraut & 2 & 1 & A2 & L. curvatus \\
\hline L. curvatus & LV $19 \S$ & Pork meat & 7 & 2 & $\mathrm{~A} 2$ & L. curvatus \\
\hline L. curvatus & R 57§, R 79, R126 & & 9 & 2 & A2 & L. curvatus \\
\hline L. curvatus & N $151 \S, \mathrm{N} 153 \S, \mathrm{N} 177 \S, \mathrm{N} 178 \S$ & Pork meat & 12 & 2 & $\mathrm{~A} 2$ & L. curvatus \\
\hline L. curvatus & T $411 \S, \mathrm{T} 662$ & Pork meat & 5 & 2 & A2 & L. curvatus \\
\hline L. sakei & CTC 041, CTC 287, CTC 427 & Sausage & 3 & 7 & B1 & L. sakei \\
\hline L. sakei & 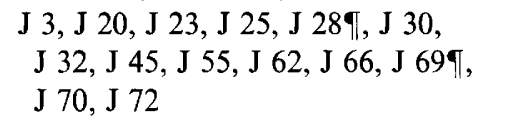 & Sausage & 6 & 7 & B1 & L. sakei \\
\hline L. sakei & J 38, J 52ף, J 53ף, J 56 & Sausage & 6 & 5 & B1 & L. sakei \\
\hline L. sakei & J 321 & Sausage & 6 & 4 & B1 & L. sakei \\
\hline L. sakei & LV 5 & Pork meat & 7 & 5 & B1 & L. sakei \\
\hline L. sakei & LV 34ף & Beef meat & 7 & 7 & B1 & L. sakei \\
\hline L. sakei & T 3009 & Beef meat & 5 & 5 & B1 & L. sakei \\
\hline L. sakei & T 504 & Pork meat & 5 & 7 & B1 & L. sakei \\
\hline L. sakei & T 518, T 557 & Pork meat & 5 & 5 & B1 & L. sakei \\
\hline L. sakei & T 732ף & Meat & 5 & 7 & B1 & L. sakei \\
\hline L. sakei & TISTR 911 & & 10 & 6 & B1 & L. sakei \\
\hline L. sakei & V 553ף, YME 344ণ, YMW 54ף & Meat & 8 & 7 & B1 & L. sakei \\
\hline L. sakei & CTC 014, CTC 335, CTC 429 & Sausage & 3 & 7 & B2 & L. sakei \\
\hline L. curvatus & CTC 163 & Sausage & 3 & 5 & & L. sakei \\
\hline L. sakei & DSM 6747ף & & 1 & 7 & B2 & L. sakei \\
\hline L. sakei & 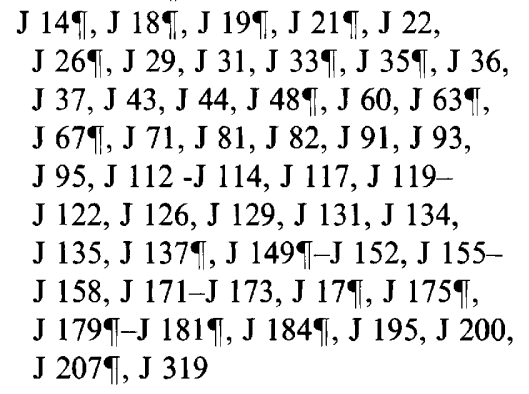 & Sausage & 5 & 7 & B2 & L. sakei \\
\hline L. sakei & $\mathrm{J}$ 64ף & Sausage & 6 & 4 & B2 & L. sakei \\
\hline L. sakei & J 54, J 1869 & Sausage & 6 & 5 & B2 & L. sakei \\
\hline L. sakei & $\mathrm{J} 160 \times 19$ & Horse meat & 6 & 7 & B2 & L. sakei \\
\hline L. sakei & J G39, J G139 & Beef meat & 6 & 7 & B2 & L. sakei \\
\hline L. sakei & J GV1 & Pork meat & 6 & 7 & B2 & L. sakei \\
\hline L. sakei & $\begin{array}{l}\text { LTH } 675, \text { LTH } 677, \text { LTH } 938, \\
\text { LTH 939, LTH } 945\end{array}$ & Sausage & 2 & 7 & B2 & L. sakei \\
\hline L. sakei & LTH 1764 & Sauerkraut & 2 & 7 & B2 & L. sakei \\
\hline L. bavaricus & $\begin{array}{l}\text { LTH 2068, LTH 2069, LTH } 2070, \\
\text { LTH 2071, LTH } 2076\end{array}$ & Sauerkraut & 2 & 6 & B2 & L. sakei \\
\hline L. sakei & LV $21 \pi$ & Pork meat & 7 & 7 & B2 & L. sakei \\
\hline L. sakei & LV 52, LV 59 & Lamb meat & 7 & 7 & B2 & L. sakei \\
\hline L. sakei & LV 82ף, LV 92 & Bacon & 7 & 7 & B2 & L. sakei \\
\hline L. sakei & L 1109 & Starter & 11 & 7 & B2 & L. sakei \\
\hline
\end{tabular}


Table 1 (cont.)

\begin{tabular}{|c|c|c|c|c|c|c|}
\hline $\begin{array}{l}\text { Name as } \\
\text { received }\end{array}$ & Strain number & Isolated from: & Source* & $\begin{array}{c}\text { Phenotypic } \\
\text { group } \dagger\end{array}$ & $\begin{array}{l}\text { RAPD } \\
\text { group! }\end{array}$ & Proposed name \\
\hline L. sakei & T 205T, T 475 & Beef meat & 5 & 7 & B2 & L. sakei \\
\hline L. sakei & T 214ๆ, T 2409 & Beef meat & 5 & 4 & $\mathrm{~B} 2$ & L. sakei \\
\hline L. sakei & 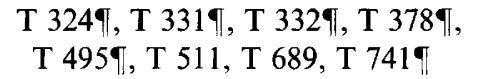 & Pork meat & 5 & 7 & B2 & L. sakei \\
\hline L. sakei & T 3819 & Pork meat & 5 & 5 & B2 & L. sakei \\
\hline L. sakei & TISTR 890 & & 10 & 7 & B2 & L. sakei \\
\hline L. sakei & Y $216 \rrbracket$, YMH 243ף, YMW 557 & Meat & 8 & 7 & $\mathrm{~B} 2$ & L. sakei \\
\hline L. sakei & $\operatorname{ATCC} 15521^{\mathrm{T}}$ & Sakei starter & 4 & 7 & B2 & L. sakei \\
\hline L. graminis & DSM $20719^{\mathrm{T}}$ & Silage & 1 & 10 & $\mathrm{C}$ & L. graminis \\
\hline L. plantarum & ATCC $14917^{\mathrm{T}}$ & & 4 & ND & $\mathrm{D}$ & L. plantarum \\
\hline L. pentosus & ATCC $8041^{\mathrm{T}}$ & Silage & 4 & 8 & $\mathrm{E}$ & L. pentosus \\
\hline L. curvatus & Т $497 \S$ & Pork meat & 5 & 8 & $\mathbf{E}$ & L. pentosus \\
\hline $\begin{array}{l}\text { Lactobacillus } \\
\text { sp. }\end{array}$ & T 720 & Starter & $?$ & 8 & $\mathrm{E}$ & L. pentosus \\
\hline L. curvatus & R $102 \mathrm{e} \S$ & Meat & 9 & 8 & $\mathrm{E}$ & L. pentosus \\
\hline L. sakei & T 392ণ, T 589 & Pork meat & 5 & 9 & $\mathrm{~F}$ & $?$ \\
\hline $\begin{array}{l}\text { Lactobacillus } \\
\text { sp. }\end{array}$ & T 6929 & & 5 & 9 & & $?$ \\
\hline
\end{tabular}

* 1, Deutsche Sammlung von Mikroorganismen und Zellkulturen, Braunschweig, Germany; 2, Institut für Lebensmitteltechnologie, Universität Hohenheim, Germany; 3, IRTA Meat Technology Centre, Monells, Spain (Hugas et al., 1993); 4, American Type Culture Collection, Manassas, VA, USA; 5, Station de Recherches sur la Viande, INRA Theix, France (Montel et al., 1991); 6, Laboratoire de Recherches sur la Viande, INRA Jouy-en-Josas, France; 7, ARC Meat Research Institute, Langford, Bristol, UK (Shaw \& Harding, 1984); 8, Japan (Morishita \& Shiromizu, 1986); 9, G. Reuter, Institute of Meat Hygiene and Technology, Free University of Berlin, Berlin, Germany; 10, Valyasevi, Thailand; 11, Texel, France; 12, MATFORSK Norwegian Food Research Institute, Ås, Norway (Nissen \& Dainty, 1995).

$\dagger$ This work (Table 2).

$\ddagger$ This work (Fig. 1).

§Genetically identified by DNA-DNA hybridization or rDNA probing and affiliated with L. curvatus DNA (Montel et al., 1991; Nissen \& Dainty, 1995).

T Genetically identified by DNA-DNA hybridization and affiliated with L. sakei DNA (Montel et al., 1991; M.-C. Montel, personal communication).

ND, Not determined.

conducted on 50 strains (Klein et al., 1996) and two sub-groups were described for each species. The $L$. sakei sub-groups were not differentiated by biochemical features, whereas the $L$. curvatus sub-groups were defined according to their utilization or not of melibiose. Genotypically, numerical analysis of RAPD patterns from 39 strains of $L$. sakei and $L$. curvatus also revealed two sub-groups within $L$. curvatus and $L$. $s a k e i$, with one $L$. curvatus sub-group more closely linked to one of the two $L$. sakei than to the other $L$. curvatus sub-group (Torriani et al., 1996). Protein pattern-and RAPD-based sub-groups coincided in the 24 strains that were analysed by both methods. At present, it is not possible to rapidly assign strains to these $L$. sakei genetic sub-groups. Comparison of $16 \mathrm{~S}$ rRNA sequences from $L$. curvatus, Lactobacillus graminis and $L$. sakei showed that these species form a tight and distinct phylogenetic sub-group of the Lactobacillus casei group (Schleifer \& Ludwig, 1995). These highly related species could be clearly delineated by DNA-DNA hybridization experiments (Beck et al.,
1988; Montel et al., 1991; Klein et al., 1996). Lactobacillus bavaricus, the previous name of a fourth species, was shown to be the junior synonym of either L. sakei or L. curvatus (Kagermeier-Callaway \& Lauer, 1995).

The objectives of this study were to evaluate the genetic and biochemical diversity of the $L$. sakei/L. curvatus group, to compare its genetic and biochemical diversity, and to provide rapid and reliable tools for differentiating and detecting the group(s) and subgroup(s). For this, we used RAPD for several reasons: (i) it has proven to be a sensitive and efficient molecular method for distinguishing between different strains of a species or of related species; (ii) its rapidity renders it extremely attractive given the large size of our strain collection; (iii) with numerical analysis of data, it allows the grouping and the identification of strains (Vauterin \& Vauterin, 1992); and (iv) RAPD products can serve as probes or can be sequenced to provide oligonucleotide probes and primers for specifically 
Table 2. Phenotypic groups among the collection of strains

\begin{tabular}{|cccccc|}
\hline Phenotype no. & $\begin{array}{c}\text { Hydrolysis of } \\
\text { arginine }\end{array}$ & $\begin{array}{c}\text { Fermentation of } \\
\text { melibiose }\end{array}$ & $\begin{array}{c}\text { Presence of } \\
\text { catalase activity }\end{array}$ & $\begin{array}{c}\text { Production of } \\
\text { D-lactate }\end{array}$ & $\begin{array}{c}\text { Fermentation } \\
\text { of xylose }\end{array}$ \\
\hline 1 & - & - & - & - & - \\
2 & - & - & - & + & - \\
3 & - & - & + & + & - \\
4 & + & + & + & + & - \\
5 & + & - & + & - & - \\
6 & + & + & + & + & - \\
7 & + & + & + & + & + \\
8 & - & + & - & - & - \\
9 & + & - & ND & + & + \\
10 & ND & - & & \\
\hline
\end{tabular}

ND, Not determined.

Table 3. List of primers, PCR conditions, size of PCR products and specificity

\begin{tabular}{|c|c|c|c|c|}
\hline $\begin{array}{l}\text { Primer } \\
\text { pair(s) }\end{array}$ & Sequence $5^{\prime}-3^{\prime *}$ & $\begin{array}{c}\text { Duration of } \\
\text { annealing/number } \\
\text { of cycles }\end{array}$ & $\begin{array}{l}\text { Size of PCR } \\
\text { product(s) } \\
\text { (bp) }\end{array}$ & Specificity \\
\hline Ala $/$ Ala $^{\prime} \dagger$ & CTGCTGGGACGATTTG/CTGCTGGGACCATGTG & $0 \mathrm{~min} / 20$ cycles & 1840 & L. curvatus \\
\hline $\mathrm{A} 1 \mathrm{~b} / \mathrm{A} 1 \mathrm{~b}^{\prime} \dagger$ & CTGCTGGGACCATTATTG/CTGCTGGGACACAATATG & $1 \mathrm{~min} / 30$ cycles & 1470 & Not tested \\
\hline $\mathrm{A} 1 \mathrm{c} / \mathrm{A} 1 \mathrm{c}^{\prime} \dagger$ & GGAGGGTGTTCAGGAC/GGAGGGTGTTGATAGG & $0 \mathrm{~min} / 20$ cycles & 260 & L. curvatus \\
\hline $\mathrm{Bla} / \mathrm{Bla}^{\prime} \dagger$ & CTGCTGGGACCAATT/CTGCTGGGACGAAAAG & $0 \mathrm{~min} / 20$ cycles & 750 & $\begin{array}{l}\text { L. sakei } \\
\text { sub-group B1 } \\
\text { (absent in B2) }\end{array}$ \\
\hline $\mathrm{B} 2 \mathrm{a} / \mathrm{B} 2 \mathrm{a}^{\prime} \dagger$ & CTGCTGGGACCTTAA/CTGCTGGGACTGAAG & $1 \mathrm{~min} / 30$ cycles & 1700 & $\begin{array}{l}\text { L. sakei } \\
\text { sub-group B2 }\end{array}$ \\
\hline 16/Lct & GCTGGATCACCTCCTTTC/TTGGTACTATTTAATTCTTAG & $0 \mathrm{~min} / 20$ cycles & 220 & L. curvatus \\
\hline $16 / \mathrm{Ls}_{+}^{+}$ & GCTGGATCACCTCCTTTC/ATGAAACTATTAAATTGGTAC & $0 \mathrm{~min} / 20$ cycles & 220 & L. sakei \\
\hline
\end{tabular}

* The first 10 nucleotides in the sequence (underlined) correspond to the sequence of the 10-mer RAPD primer.

$\dagger$ This work.

$\ddagger$ Berthier \& Ehrlich (1998).

detecting groups of strains (Manulis et al., 1994; Rodriguez et al., 1995; Bazzicalupo \& Fani, 1996; Pooler et al., 1996). RAPD analysis was applied to a collection of 165 isolates and five type strains representing different lactic acid bacteria. The isolates were isolated from diverse biotopes and geographic origins and were previously assigned to the $L$. curvatus $/ L$. sakei group. This work provides new insights into the phenotypic and genotypic diversity of $L$. curvatus and L. sakei.

\section{METHODS}

Strains used. The bacterial isolates examined and their sources are listed in Table 1. Many of them were previously included in the DNA-DNA hybridization studies of Montel et al. (1991). They were routinely grown in MRS broth or on MRS agar plates (de Man et al., 1960) at $30^{\circ} \mathrm{C}$.

\section{Phenotypic analysis}

For each strain, a liquid culture was grown from a single colony. Subcultures were used either for phenotypic analysis or for extracting DNA.

Production of D-lactate. D-Lactate was detected enzymically in the supernatant fluid of $3 \mathrm{~d}$ cultures using D-lactate dehydrogenase as indicated by the manufacturer (Boehringer Mannheim).

Presence of haem-dependent catalase. Cells were grown aerobically at $30^{\circ} \mathrm{C}$ in MRS broth containing $5 \mathrm{~g}$ glucose $1^{-1}$, supplemented with $30 \mu \mathrm{g}$ haematin $1^{-1}$. After $24 \mathrm{~h}$, catalase activity was assessed by the presence of an effervescence when adding $0.6 \% \mathrm{H}_{2} \mathrm{O}_{2}$.

Melibiose and xylose fermentation. Cells were grown anaerobically for $3 \mathrm{~d}$ at $30^{\circ} \mathrm{C}$, under a $\mathrm{H}_{2} / \mathrm{CO}_{2}$ atmosphere (GasPack System; BBL) in MRS broth without glucose, either unsupplemented or supplemented $\left(1 \mathrm{~g}^{-1}\right)$ with xylose or melibiose. Fermentation was positive when the culture 
growth improved and/or the $\mathrm{pH}$ of the culture broth dropped in the presence of the carbohydrate.

Arginine hydrolysis. Cells were grown anaerobically for $3 \mathrm{~d}$ at $30{ }^{\circ} \mathrm{C}$ under a $\mathrm{H}_{2} / \mathrm{CO}_{2}$ atmosphere (Gas-Pack System; $\mathrm{BBL}$ ), in a broth containing $\left(\mathrm{l}^{-1}\right): 10 \mathrm{~g}$ meat extract (Difco); $10 \mathrm{~g}$ proteose peptone no. 3 (Difco) $5 \mathrm{~g}$ universal peptone (Merck); $1 \mathrm{ml}$ Tween $80 ; 1 \mathrm{~g}$ glucose; and $30 \mathrm{mg} \mathrm{MnSO}_{\mathrm{a}}$. Broths were either unsupplemented or supplemented with $3 \mathrm{~g}$ arginine $\mathrm{l}^{-1}$. Production of ammonia was detected by the rise of $\mathrm{pH}$ in the culture containing arginine.

\section{RAPD analysis}

DNA isolation. Total DNA was extracted from a culture inoculated with a single colony as described previously (de los Reyes-Gavilan et al., 1992). The quantity of DNA was estimated by comparison with known standards in ethidium bromide-stained $0.7 \%$ agarose gels.

Primers used. Fifteen arbitrarily-designed primers of 10 nucleotides were tested initially by screening DNA from three isolates obtained from different sources in RAPDPCR amplification assays. The suitability of each primer was scored on the basis of intensity and distribution of bands. Some primers gave reproducible banding profiles with a sufficient number of bands to be discriminatory for each isolate. Two of them were selected for performing subsequent RAPD analysis. Their sequences were $5^{\prime}$ CTGCTGGGAC $3^{\prime}$ for primer 1 and 5' GGAGGGTGTT $3^{\prime}$ for primer 2 .

PCR amplification. PCR amplification was performed in $100 \mu \mathrm{l}$ volumes containing $20-100 \mathrm{ng}$ DNA, $1.5 \mathrm{mM} \mathrm{MgCl}_{2}$, $0.5 \mu \mathrm{M}$ primer, $200 \mu \mathrm{M}$ each dNTP and $2.5 \mathrm{U}$ Taq DNA polymerase (Appligène) in $10 \mathrm{mM}$ Tris $/ \mathrm{HCl}(\mathrm{pH}$ 9.0). PCR reactions were carried out in a thermal cycler (Perkin Elmer 9600 ) programmed for 30 cycles of amplification of $1 \mathrm{~min}$ at $94{ }^{\circ} \mathrm{C}, 2 \mathrm{~min}$ at $36^{\circ} \mathrm{C}$ and 2 min at $72^{\circ} \mathrm{C}$.

Electrophoresis. The PCR reaction mixes $(20 \mu \mathrm{l})$ were electrophoresed in $1 \%$ Seakem GTG agarose (Tebu) gels in TBE (90 mM Tris/borate, $1 \mathrm{mM}$ EDTA). Each gel contained 10 lanes of PCR products and three lanes of a $123 \mathrm{bp}$ ladder (Gibco-BRL) as normalization reference. This normalization reference was applied every five samples. Gels were then stained with ethidium bromide and photographed with Polaroid film 665 . Negative photographs were digitized with a laser densitometer (Hewlett Packard ScanJet IIcx/T).

Computer analysis. The data set was analysed with the software package GelCompar (version 3.1 ; Applied Maths, Kortrijk, Belgium). The analysis included: (i) registration of the electrophoretic patterns; (ii) normalization of the densitometric traces and subtraction of background noise; (iii) grouping of strains by the Pearson product-moment correlation coefficient; and (iv) cluster analysis by UPGMA (unweighted pair group method using arithmetic means). PCR products larger than 2460 bp were not included in the analysis because of their poor electrophoretic resolution. The normalized densitometric traces obtained with each of the primers were assembled to obtain a single combined densitometric trace for each strain.

DNA sequence analysis. The RAPD-PCR fragments were gel-purified and cloned into a pBluescript II SK $(+)$ plasmid vector (Stratagene). Both strands of DNA of four different recombinant clones were at least partially sequenced. The nucleotide sequence of DNA was determined with the 373 automated DNA sequencer (Applied Biosystems) according to the manufacturer's instructions. Nucleotide sequence

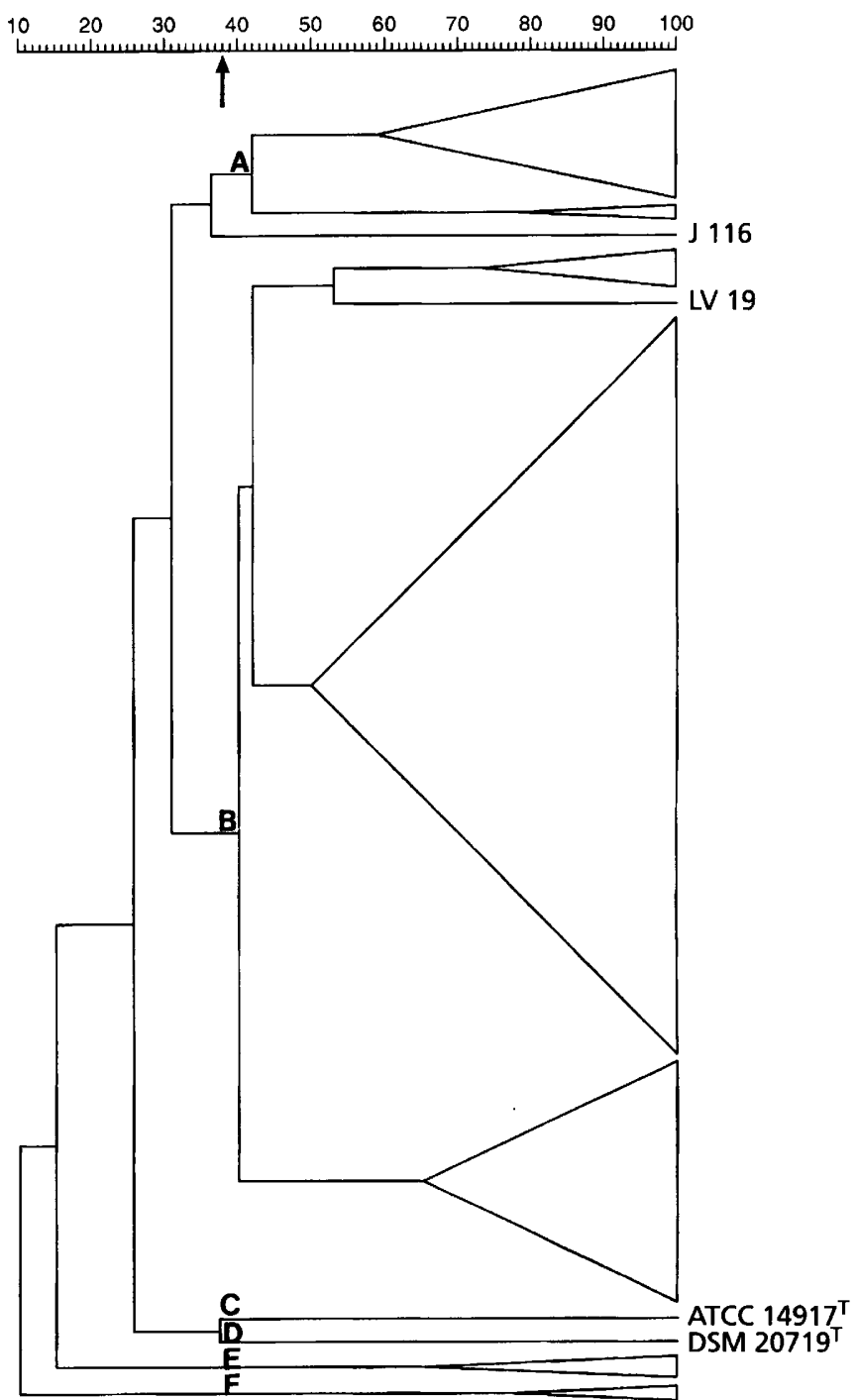

Fig. 1. Dendrogram generated from RAPD profiles of 170 isolates. The scale indicates the similarity level (Pearson coefficient level $\times 100$ ). Profiles were grouped using the UPGMA method. Groups of profiles were reduced to white triangles and lettered A-F. The arrow marks the cut-off value at $38 \%$ to define the RAPD groups within the dendrogram. The names of some strains are indicated on the right.

data were analysed with version 8 of the GCG software package (Genetics Computer Group, Madison, WI, USA).

PCR assays for diagnostic amplification. PCR was performed with $20 \mu \mathrm{l}$ volumes containing $1 \times$ PCR buffer without $\mathrm{MgCl}_{2}$ (Boehringer Mannheim), $2.5 \mathrm{mM} \mathrm{MgCl}_{2}, 0.3 \mu \mathrm{M}$ each dNTP, $0.5 \mathrm{U}$ Taq DNA polymerase (Boehringer Mannheim), $20 \mathrm{ng}$ template DNA and $0.3 \mu \mathrm{M}$ each primer (Table 3). The amplification cycles always comprised a denaturation step of $1 \mathrm{~min}$ at $94^{\circ} \mathrm{C}$, a synthesis step of $1 \mathrm{~min}$ at $72{ }^{\circ} \mathrm{C}$ and an annealing temperature of $53{ }^{\circ} \mathrm{C}$. The number of cycles and the annealing time depended on the primers used and are listed in Table 3 . PCR products were analysed by agarose gel electrophoresis and stained with ethidium bromide. 


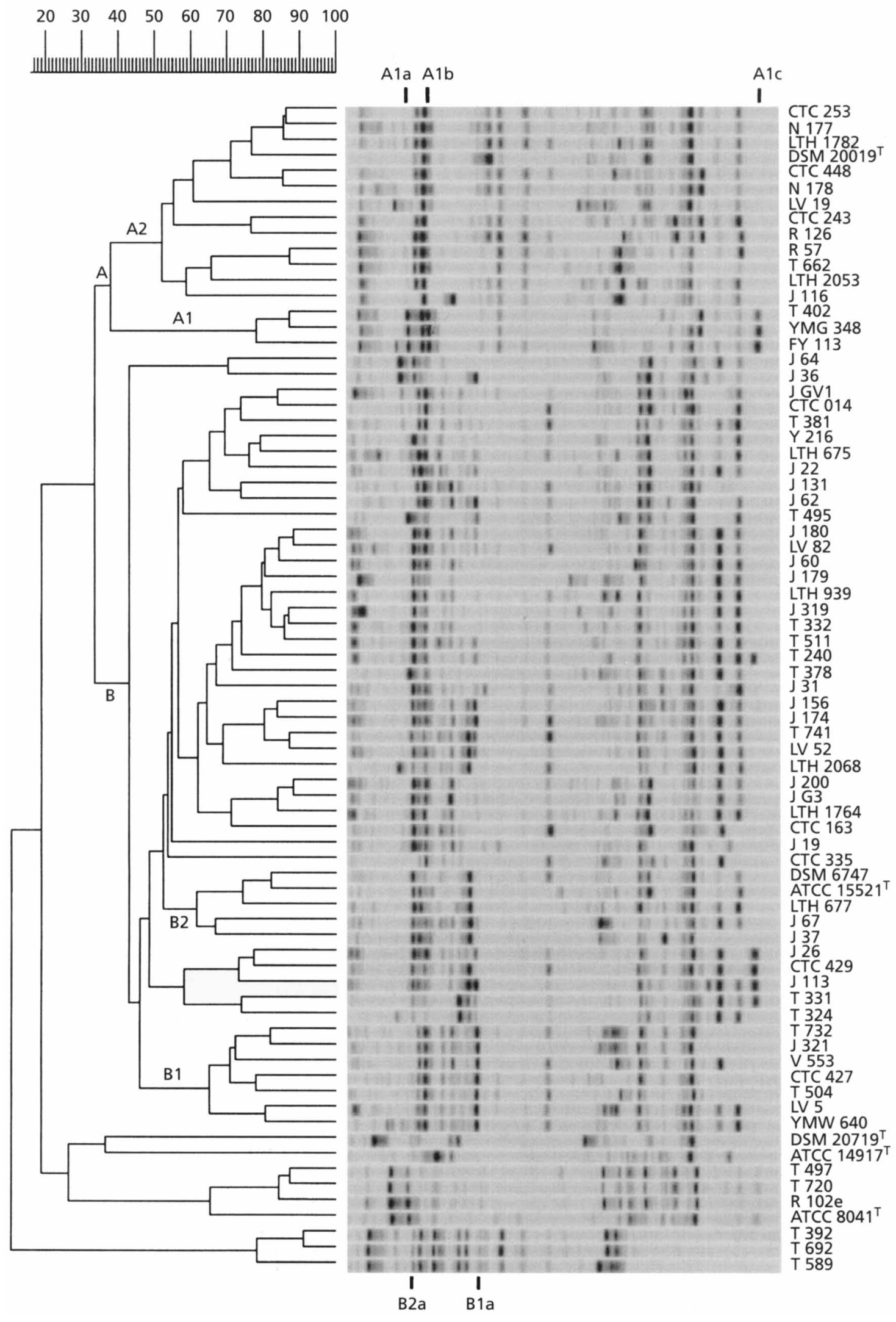

Fig. 2. RAPD profiles of 75 isolates and generated dendrogram. The scale indicates the similarity level (Pearson coefficient level $\times 100$ ). Profiles were grouped using the UPGMA method. RAPD groups and sub-groups, as well as selected RAPD fragments, are lettered. 


\section{RESULTS}

\section{Biochemical analysis: phenotypic diversity among isolates}

We examined five biochemical features usually used to differentiate between $L$. sakei, $L$. graminis and $L$. curvatus species: arginine hydrolysis in the presence of a low glucose concentration; melibiose and xylose fermentation; the presence of haem-dependent catalase; and the production of D-lactate. Typically, (i) $L$. sake $i$ hydrolyses arginine, ferments melibiose and has catalase activity, but $L$. curvatus does not, (ii) $L$. graminis ferments xylose, but $L$. sakei and $L$. curvatus do not, (iii) the three species produce L- and D-lactate (Beck et al., 1988; Wolf \& Hammes, 1988; Montel et al., 1991). As shown in Table 2, atypical phenotypes were found for some of the $L$. sakei or $L$. curvatus isolates studied. Novel atypical phenotypes were observed: three isolates (T 402, YMG 348 and FY 113) identified as L. curvatus by DNA-DNA hybridization, exhibited $L$. curvatus features, except that catalase activity was present (phenotypic group 3; Table 2) and inversely, four $L$. sakei isolates (J 64, J 321, T 214 and T 240) exhibited $L$. sakei features, except that catalase activity was absent (phenotypic group 4; Table 2). We did not find any melibiose-positive $L$. curvatus isolates, although some of the isolates given to us were believed to be positive. Two L. curvatus isolates ( $R 102 \mathrm{e}$ and $\mathrm{T}$ 497) were found to be melibiose-positive and also exhibited all biochemical features of Lactobacillus pentosus. As previously mentioned (KagermeierCallaway \& Lauer, 1995; Samelis et al., 1995), we observed melibiose-negative $L$. sakei isolates, as well as D-lactate-negative $L$. curvatus and $L$. sake $i$ isolates. The latter were formerly named $L$. bavaricus (Kagermeier-Callaway \& Lauer, 1995). Three isolates given to us as L. sakei (T 392, T 589 and T 692) exhibited a phenotype completely different from that of L. sakei (phenotypic group 9; Table 2).

\section{RAPD-PCR analysis: genotypic diversity among isolates}

Reproducibility. To ensure reproducible RAPD results, we strictly controlled the parameters of RAPD-PCR and electrophoresis and we assessed the level of variation among different profiles from a single isolate. Total DNA from three isolates was prepared independently five times and assayed by independent RAPD. All profiles of an isolate yielded similarity levels of $88 \%$ or higher when computed and clustered by UPGMA (not shown).

RAPD groups in the isolate collection : delineation of species. Numerical analysis of the 170 combined PCR profiles clustered by UPGMA enabled the plotting of the dendrogram shown in Fig. 1. Profiles differing by more than $88 \%$, termed 'selected' here, are displayed in Fig. 2.

Two major groups, $\mathrm{A}$ and $\mathrm{B}$, were defined at the similarity level of $38 \%$. Group A comprised the $L$. curvatus type strain and 20 isolates, including nine that were previously affiliated with $L$. curvatus by DNA-DNA hybridization or rDNA probing (Table 1). Group B comprised the L. sakei type strain and 138 isolates, including 49 that were previously affiliated with $L$. sakei by DNA-DNA hybridization (Table 1). Isolates formerly named $L$. bavaricus were placed in either the $L$. sakei or the $L$. curvatus groups.

In addition to the two major groups, four minor groups were defined. They were weakly linked to the major groups and comprised from one to four strains. One of these groups was composed of the $L$. graminis type strain. Another minor group comprised the $L$. pentosus type strain and three isolates, including two that were previously affiliated with $L$. curvatus. Given their L. pentosus-like phenotypic features (phenotypic group 8; Table 2), especially their xylose utilization and present RAPD grouping, the three isolates were very likely misnamed and were members of the $L$. pentosus species. Another minor group comprised three isolates, from which two were previously affiliated with $L$. sakei. They formed a distinct phenotypic group, exhibiting features very different from those typical of L. sakei or L. curvatus (phenotypic group 9; Table 2). They also were most likely misnamed. For the misnamed isolates, we do not know whether the cultures we received were named incorrectly or whether they became contaminated during our experiments.

Isolate $\mathrm{J} 116$, identified as $L$. curvatus by DNA-DNA hybridization, was closely linked to group A (Fig. 1). As shown in Fig. 2, its profile was placed in group A when a selection of strains was analysed. Therefore, it was included in group A. Isolate LV 19, identified as $L$. curvatus by DNA-DNA hybridization, was located peripherally in group B (Fig. 1). As shown in Fig. 2, its profile was placed in group A when a selection of strains was analysed. Visual inspection of its profile clearly showed that it was misplaced within group B and better placed in group $A$.

The above results show that, after numerical analysis of the combined profiles obtained with two different primers, RAPD analysis could clearly differentiate between the species $L$. curvatus (RAPD group A), $L$. sakei (RAPD group B) and L. graminis strains previously delineated by DNA-DNA hybridization. Therefore, these conditions were routinely used for further RAPD analysis.

RAPD sub-groups: genetic diversity within $L$. sakei and $L$. curvatus isolates. Groups A and B could be subdivided into many sub-groups defined at different similarity levels.

Sub-groups defined at similarity levels of $88 \%$ or higher could be obtained. These levels corresponded to the lowest similarity level obtained by repeated RAPD analyses of the same isolate. In some cases, these subgroups comprised different isolates originating from the same sample and containing similarly sized plasmids (not shown). In this regard, they probably corresponded to isolates of the same strain. In other 
(a)

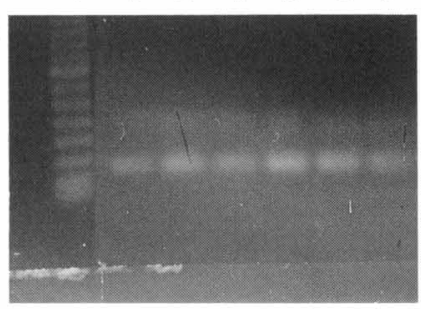

(b)

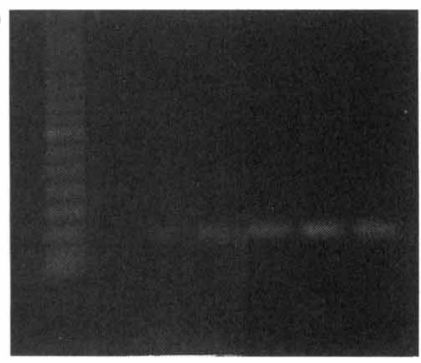

$\begin{array}{lllllllll}8 & 9 & 10 & 11 & 12 & 13 & 14 & 15 & 16\end{array}$

(c)

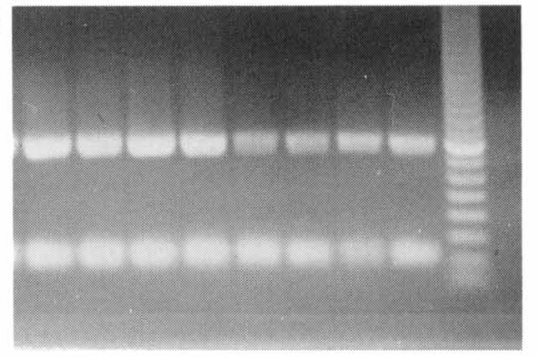

(d)

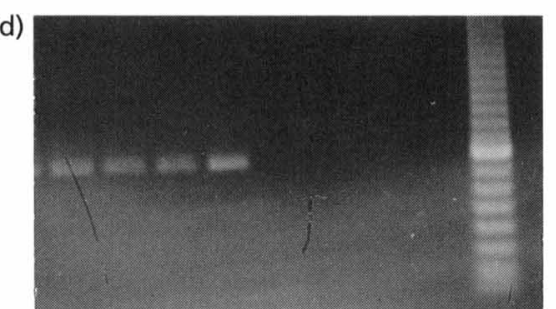

(e)

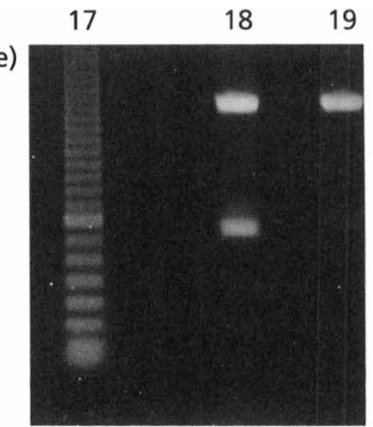

2021

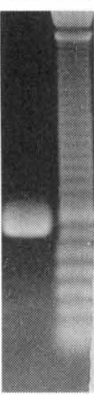

Fig. 3. PCR specificity. Amplification of L. curvatus [(a) and (b)] and L. sakei [(c), (d) and (e)] DNAs primed by the following oligonucleotides: (a) 16/LC; (b) A1C/A1C'; (c) B1a/B1a' and 16/Ls, separately then pooled; (d) B1a/B1a'; and (e) $\mathrm{B} 1 \mathrm{a} / \mathrm{B} 1 \mathrm{a}^{\prime}+\mathrm{B} 2 \mathrm{a} / \mathrm{B} 2 \mathrm{a}^{\prime}$. Reactions were carried out under conditions described in Table 3 except for (c) and (e), in which PCR conditions were $1 \mathrm{~min}$ annealing, 30 cycles. Lanes: 1, 16, 17, 21:100 bp ladder; 2-4, L. curvatus FY 113, T 402, YMG 348; 5-7, L. curvatus CTC 243, J 116, R 57; 8-11, L. sakei YMW 540, V 553, CTC 427, LV 5; 12-15, L. sakei LTH 2068, Theix 378, LV 82, Theix 495; 18, L. sakei LV 82;19, L. sakei J 60; 20, L. sakei T 732.

cases, the sub-groups were composed of isolates originating from different samples, sometimes obtained from different countries and at different times. This indicates that similar strains can be widely dispersed.

Profiles differing by more than $88 \%$ are displayed in Fig. 2. Group A comprised 16 such profiles and group B comprised 50 . Similarity values indicated that the $L$. sakei and $L$. curvatus strains were genetically diverse. Similarity values among the $L$. sake $i$ and $L$. curvatus isolates were $43-87 \%$ and $52-87 \%$, respectively. The new groups A and B were also composed of subgroups.

Two sub-groups, A1 and A2, were defined for group A. A1 was composed of 13 profiles, including that of the L. curvatus type strain. A2 was composed of the three profiles of isolates which were phenotypically catalase-positive, a feature common to $L$. sakei.

Two sub-groups, B1 and B2, were defined for group B. B1 was composed of seven profiles and B2 of 40 profiles, including that of the $L$. sakei type strain. Subgroups B1 and B2 did not correlate with any of those based on the phenotypic features we analysed, including trehalose fermentation. At this stage of analysis, the profiles of three isolates, CTC $335, \mathrm{~J} 36$ and $\mathrm{J}$ 64 , were not included in any sub-group. Indeed, the profile of isolate CTC 335 was linked to sub-group B1 within the selected set of profiles (Fig. 2) and was within B2, when the entire collection was considered (Fig. 1). The profiles of isolates J 36 and J 64 separated these isolates from all others.

\section{Diagnostic PCR analysis}

Characterization of the sub-group-specific RAPD fragments. Five RAPD products were chosen on the basis of their size, intensity and specificity to sub-groups Al (fragments A1a, A1b, A1c), B1 (fragment B1a) and B2 (fragment $\mathrm{B} 2 \mathrm{a}$ ). They are marked with pointers in Fig. 2. These DNA products were cloned and partially or totally sequenced.

Design of sub-group-specific PCR primers. Sequence information was used for selecting the five PCR primer pairs listed in Table 3. Oligonucleotide primers specific for the detection of RAPD fragments consisted of the original 10-base RAPD primer plus the next 5 to 8 nucleotides as determined by sequence analysis. All primers amplified a specific product identical in size to the original cloned RAPD product (Table 3). Amplification with primer pair Alb/Alb' was poor and this primer pair was rejected.

Specificity of the PCR assays. The PCR primer pairs were tested for their specificity by using DNA from strains of $L$. graminis and the RAPD groups A and B, selected for diversity analysis (Fig. 2). All amplification assays from one DNA were conducted simultaneously with the same DNA-containing PCR mixture and aliquots were mixed together with the primer pair(s) tested. One aliquot was mixed with primer pair $16 / \mathrm{Lc}$ or 16/Ls for species identification (Berthier \& Ehrlich, 1998).

In theory, PCR with pairs Ala/A1a' and Alc/Alc' should selectively amplify the $1840 \mathrm{bp}$ and $260 \mathrm{bp}$ fragments, respectively, from DNAs of only the $L$. 
curvatus sub-group A1. However, as seen in Fig. 3, for pair Alc/Alc', it also amplified the same fragments from DNAs of $L$. curvatus sub-group A2, albeit less intensely, even when the number of cycles and the annealing time were low. Specificity was not enhanced by the addition of formamide at various concentrations (not shown). PCR with pairs Ala/Ala' and Alc/Alc' did not amplify any fragment from DNAs of $L$. sakei or $L$. graminis (data not shown). Thus, strains could be specifically identified as $L$. curvatus by testing the presence/absence of a fragment after PCR amplification with primer pairs Ala/Ala' and Alc/Alc', but not assigned reliably to a sub-group.

We expected that PCR with pairs $\mathrm{B} 1 \mathrm{a} / \mathrm{B} 1 \mathrm{a}^{\prime}$ would selectively amplify a $750 \mathrm{bp}$ fragment from DNAs of $L$. sakei sub-group B1. Such a fragment was indeed amplified only from DNAs of this sub-group under appropriate conditions ( 0 min annealing, 20 cycles; Table 3). However, under different conditions (1 min annealing, 30 cycles), amplification from some DNAs of sub-group B2 was also observed (Fig. 3). PCR with pairs $\mathrm{B} 2 \mathrm{a} / \mathrm{B} 2 \mathrm{a}^{\prime}$ should selectively amplify a $1700 \mathrm{bp}$ fragment from DNAs of $L$. sakei sub-group B2. A fragment of the expected size was indeed amplified from all the DNAs of sub-group B2, except one (LTH 2068). No fragment was amplified from DNAs of subgroup B1. PCR with primer pairs B1a/B1a' and B2a/B2a' did not amplify any fragment from DNAs of $L$. curvatus or L. graminis when the number of cycles was 30 and the annealing time was 1 min (data not shown). Thus, strains could be simultaneously identified as $L$. sakei and assigned to $L$. sakei RAPD subgroup B1 or B2 by PCR. To screen DNAs rapidly, we recommend the following procedure: primer pairs

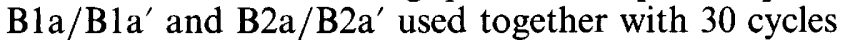
of amplification and $1 \mathrm{~min}$ of annealing. If a fragment of $1700 \mathrm{bp}$ is amplified, the strain belongs to L. sakei sub-group B2. However, if a fragment of $752 \mathrm{bp}$ is amplified, a PCR with pair Bla/Bla' is run with 20 cycles of amplification and $0 \mathrm{~min}$ of annealing. If the fragment of $752 \mathrm{bp}$ is still amplified, then the strain belongs to $L$. sakei sub-group B1. If not, the strain belongs to $L$. sakei sub-group B2. Isolates CTC $335, \mathrm{~J}$ 64 and J 36, which could not be assigned by RAPD, were included in sub-group B2.

\section{DISCUSSION}

The work presented here shows that RAPD combined with appropriate analysis tools can be used for detailed analysis of the structure of a strain collection. We found that arbitrarily selected 10-mer oligonucleotide primers, when used under well-defined conditions, are capable of reproducible amplification of random DNA fragments. With the numerical analysis of RAPD profiles, the inter- and intra-relatedness of species could be determined objectively. We used the Pearson correlation coefficient to obtain a measure of similarity for RAPD profiles, rather than other coefficients, which suffer from subjective band detection. The validity of classification by RAPD was assessed by comparing it with classifications obtained by phenotypic analysis and by the method of reference, DNA-DNA hybridization. We found an excellent agreement between these three approaches in terms of species delineation. The three methods allowed the same clear separation of the $L$. sakei, L. curvatus and L. graminis species. In comparison to the other two methods, RAPD offers the additional advantage of strain typing, since it simultaneously allows the determination of species affiliation and the differentiation of individual strains. This last property enabled us to analyse the genetic diversity within $L$. curvatus and $L$. sakei after elimination of similar isolates, and thus to delineate two L. sakei and two L. curvatus sub-groups. Affiliation of strains to one of these sub-groups can be readily determined by PCR with the diagnostic primers developed here for $L$. sakei strains and by testing for catalase activity for $L$. curvatus strains.

The detailed genetic structure of the $L$. curvatus/L. sakei group revealed by this work is somewhat different from that previously found (Klein et al., 1996; Torriani et al., 1996). Firstly, unlike the previously cited authors, we clearly separated $L$. sakei from $L$. curvatus by RAPD analysis. This finding is in agreement with results obtained in previous DNA-DNA hybridization studies which had shown differences between the whole genomes of $L$. sakei and L. curvatus (Montel et al., 1991; Torriani et al., 1996). Secondly, we did not find any melibiose-positive strains which could be regarded as L. curvatus, although the strains originated from several laboratories. The four strains N 151, N 153, N 177 and $N$ 178, reported as melibiose-positive $L$. curvatus (Nissen \& Dainty, 1995), were melibiosenegative in this study and clustered in the RAPD subgroup which includes the $L$. curvatus type strain. Strain W 54d, one of the strains belonging to the $L$. curvatus melibiose-positive group described by Klein et al. (1996) and Torriani et al. (1996), also fermented melibiose and hydrolysed arginine, but clustered in our L. sakei RAPD group. The phenotypic characterization of this strain was in accordance with our RAPD clustering, hydrolysis of arginine being a valid criterion for separating $L$. sakei from $L$. curvatus. Thirdly, the two sub-groups we identified in L. curvatus represent another subdivision to that proposed previously (Klein et al., 1996; Torriani et al., 1996), because of the different phenotypic features of the subgroups in the two studies.

In addition to the information allowing strain classification, RAPD results helped us to develop tools for the rapid characterization of the $L$. sakei/L. curvatus/L. graminis strains, both at the species and subspecies levels. By searching for subspecies-specific PCR primers from sequences of some selected RAPD fragments, we designed primer pairs which specifically amplify DNA segments from strains of $L$. curvatus or from each of the two L. sakei RAPD sub-groups. We did not succeed in designing a diagnostic primer set for the L. curvatus sub-groups. This could be due to a failure to optimize PCR conditions or to the fact that 
a primer-template mismatch near the $5^{\prime}$ end of the 10 mer primers caused RAPD polymorphism. This last explanation is supported by the hybridization studies of $L$. sakei RAPD fragments (not shown), for which we observed that polymorphism was caused by differences in priming sites rather than insertions or deletions.

It could be advantageous for laboratories to use a single diagnostic DNA fragment obtained by PCR with a pair of diagnostic primers, instead of the complex RAPD technique. However, RAPD remains necessary and useful in the search for identical isolates of the same strain.

In conclusion, RAPD can be used to evaluate the genetic diversity within species, as long as the validity of the RAPD classification at the species level is assessed. The number of primers to be used, i.e. the information needed, and the treatment of the information, i.e. the choice of the similarity coefficient and the clustering method to be used, are important parameters to be considered in elaborating a RAPD analysis protocol. RAPD then is a highly efficient method for evaluating diversity, because redundant strains can be eliminated. The practical implications of this study are numerous. For instance, the phenotypic identification key for $L$. sakei and L. curvatus was refined. Three phenotypic features, i.e. the fermentation of melibiose, the presence of catalase and the hydrolysis of arginine, were previously regarded as the main criteria for differentiating $L$. sakei from $L$. curvatus (Wolf \& Hammes, 1988; Montel et al., 1991; Samelis et al., 1995). Melibiose fermentation was considered to be a useful criterion for differentiating subspecies in L. curvatus (Torriani et al., 1996). In view of our results from RAPD and biochemical analyses, as well as previous results on DNA-DNA hybridization, a novel identification key can be proposed. It clearly appears that: (i) hydrolysis of arginine is the only phenotypic feature that can always differentiate L. sakei from L. curvatus; (ii) L. sakei exhibits at least two of the three phenotypic features; (iii) L. curvatus does not ferment melibiose; and (iv) the presence of catalase is the phenotypic criterion for differentiating two sub-groups in L. curvatus. Another implication of this study is that strains can be readily assigned to $L$. sakei or L. curvatus by using different PCR assays. The diversity of the data that can be obtained will be helpful for the rapid and reliable identification of unknown organisms.

\section{ACKNOWLEDGEMENTS}

We thank all the laboratories which supplied strains and P. Tailliez for help in designing RAPD experiments.

\section{REFERENCES}

Bazzicalupo, M. \& Fani, R. (1996). The use of RAPD for generating specific DNA probes for microorganisms. Methods Mol Biol 50, 155-175.
Beck, R., Weiss, N. \& Winter, J. (1988). Lactobacillus graminis sp. nov., a new species of facultatively heterofermentative lactobacilli surviving at low $\mathrm{pH}$ in grass silage. Syst Appl Microbiol 10, 279-283.

Berthier, F. \& Ehrlich, S. D. (1998). Rapid species identification within two groups of closely related lactobacilli using PCR primers that target the $16 \mathrm{~S} / 23 \mathrm{~S}$ rRNA spacer region. FEMS Microbiol Lett 161, 97-106.

Döring, B., Ehrhardt, S., Lücke, F.-K. \& Schillinger, U. (1988). Computed-assisted identification of lactic acid bacteria from meats. Syst Appl Microbiol 11, 67-74.

Egan, A. F. (1983). Lactic acid bacteria of meat and meat products. Antonie Leeuwenhoek 4, 327-336.

Hammes, W. P., Bantleon, A. \& Min, S. (1990). Lactic acid bacteria in meat fermentation. FEMS Microbiol Lett 87 , 165-174.

Hugas, M., Garriga, M., Aymerich, T. \& Monfort, J. M. (1993). Biochemical characterization of lactobacilli from dry fermented sausages. Int J Food Microbiol 18, 107-113.

Kagermeier-Callaway, A. S. \& Lauer, E. (1995). Lactobacillus sakei Katagiri, Kitahara, and Fukami 1934 is the senior synonym for Lactobacillus bavaricus Stetter and Stetter 1980. Int J Syst Bacteriol 45, 398-399.

Kandler, O. \& Weiss, N. (1986). Regular, nonsporing grampositive rods. In Bergey's Manual of Systematic Bacteriology, vol. 2, pp. 1208-1234. Edited by J. G. Holt \& P. H. A. Sneath. Baltimore: Williams \& Wilkins.

Klein, G., Dicks, L. M. T., Pack, A., Hack, B., Zimmermann, K., Dellaglio, F. \& Reuter, G. (1996). Emended descriptions of Lactobacillus sakei (Katagiri, Kitahara, and Fukami) and Lactobacillus curvatus (Abo-Elnega and Kandler): numerical classification revealed by protein fingerprinting and identification based on biochemical patterns and DNA/DNA hybridizations. Int $J$ Syst Bacteriol 46, 367-376.

de Man, J. C., Rogosa, M. \& Sharpe, M. E. (1960). A medium for the cultivation of lactobacilli. $J$ Appl Bacteriol 23, 130-135.

Manulis, S., Valinsky, L., Lichter, A. \& Gabriel, D. W. (1994). Sensitive and specific detection of Xanthomonas campestris pv. pelargonii with DNA primers and probes identified by Randomly Amplified Polymorphic DNA analysis. Appl Environ Microbiol 60, 4094-4099.

Montel, M.-C., Talon, R., Fournaud, J. \& Champomier, M.-C. (1991). A simplified key for identifying homofermentative Lactobacillus and Carnobacterium spp. from meat. $J$ Appl Bacteriol 70, 469-472.

Nissen, H. \& Dainty, R. (1995). Comparison of the use of rRNA probes and conventional methods in identifying strains of Lactobacillus sakei and Lactobacillus curvatus from meat. Int $J$ Food Microbiol 25, 311-315.

Pooler, M. R., Ritchie, D. F. \& Hartung, J. S. (1996). Genetic relationships among strains of Xanthomonas fragariae based on random amplified polymorphic DNA PCR, repetitive extragenic palindromic PCR, and enterobacterial repetitive intergenic consensus PCR data and generation of multiplexed PCR primers useful for the identification of this phytopathogen. Appl Environ Microbiol 62, 3121-3127.

de los Reyes-Gavilan, C. G., Limsowtin, G. K. Y., Tailliez, P., Séchaud, L. \& Accolas, J.-P. (1992). A Lactobacillus helveticusspecific probe detects restriction fragment length polymorphism in this species. Appl Environ Microbiol 5, 3429-3432. 
Rodriguez, J. G., Mejia, G. A., Del Portillo, P., Patarroyo, M. E. \& Murillo, L. A. (1995). Species-specific identification of Mycobacterium bovis by PCR. Microbiology 141, 2131-2138.

Morishita, Y. \& Shiromizu, K. (1986). Characterization of lactobacilli from meat and meat products. Int J Food Microbiol 3, 19-29.

Samelis, J., Tsakalidou, E., Metaxopoulos, J. \& Kalantzopoulos, G. (1995). Differentiation of Lactobacillus sakei and Lactobacillus curvatus isolated from naturally fermented dry salami by SDSPAGE of whole-cell proteins. $J$ Appl Bacteriol 78, 157-163.

Schillinger, U. \& Lücke, F.-K. (1987). Identification of lactobacilli from meat and meat products. Food Microbiol 4, 199-208.

Schleifer, K. H. \& Ludwig, W. (1995). Phylogeny of the genus Lactobacillus and related genera. Syst Appl Microbiol 18, 461-467.

Shaw, B. G. \& Harding, C. D. (1984). A numerical taxonomy study of lactic acid bacteria from vacuum-packed pork, lamb and bacon. J Appl Bacteriol 56, 25-40.

Torriani, S., Van Reenen, C. A., Klein, G., Reuter, G., Dellaglio, F. \& Dicks, L. M. T. (1996). Lactobacillus curvatus subsp. curvatus subsp. nov. and Lactobacillus curvatus subsp. melibiosis subsp. nov. and Lactobacillus sakei subsp. sakei subsp. nov. and Lactobacillus sakei subsp. carnosus subsp. nov., new subspecies of Lactobacillus curvatus Abo-Elnaga and Kandler 1965 and Lactobacillus sakei Katagari, Kitahara, and Fukami 1934 (Klein et al., 1996; emended descriptions), respectively. Int $J$ Syst Bacteriol 46, 1158-1163.

Vauterin, L. \& Vauterin, P. (1992). Computer-aided objective comparison of electrophoretic patterns for grouping and identification of microorganisms. European Microbiol 1, 37-41.

Wolf, G. \& Hammes, W. P. (1988). Effect of hematin on the activities of nitrite reductase and catalase in lactobacilli. Arch Microbiol 149, 220-224. 